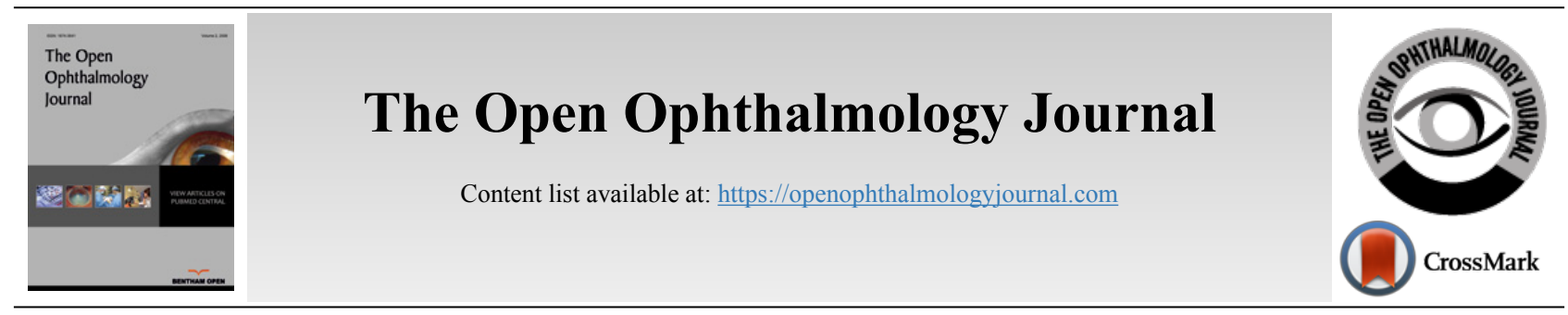

RESEARCH ARTICLE

\title{
Corneal Indices Determined with Pentacam in Possible Candidates for Corneal Refractive Surgery
}

\author{
Eduardo R. Alvarez, ${ }^{1, *}$, Giuseppe M. Montesinos ${ }^{2}$, Diego M. Torres Piedra ${ }^{2}$, Nataly T. Palacios ${ }^{2}$ and Osvaldo F. Téllez ${ }^{3}$ \\ ${ }^{1}$ University of Cuenca. Exilaser Ophthalmological Center, Cuenca, Ecuador \\ ${ }^{2}$ Exilaser Ophthalmological Center, Cuenca, Ecuador \\ ${ }^{3}$ Postgraduate Institute. Technical University of Manabi, Manabi, Ecuador
}

\begin{abstract}
:
Objective:

To describe the level of correlation of clinical refractive variables with corneal indices in Pentacam Scheimpflug tomography, demonstrate the usefulness of the study of corneal indices in the diagnosis of keratoconus (KC), and identify the corneal indexes with the greatest influence on the diagnosis of $\mathrm{KC}$.

Methods:

A descriptive, retrospective, and cross-sectional study was conducted in 69 patients (138 eyes) with refractive disorders, possible candidates for corneal refractive surgery, at the Exilaser Ophthalmological Center, Cuenca, Ecuador, from March to August 2019. Corneal indices were studied using Pentacam. Statistical correlation methods, Levene's test, Fisher's exact test, Cramérs' V coefficient, and multiple correspondence analyses were used.

Results:

The variables refractive cylinder and central keratometry had a direct correlation with the corneal indices $(\mathrm{p}<0.001)$. An inverse correlation was obtained between central pachymetry and corneal indices $(\mathrm{p}<0.001)$. A high level of dependence on central $\mathrm{KC}$ index $(\mathrm{CKI})(\mathrm{Cramér} \mathrm{V}=0.785)$ and $\mathrm{KC}$ index (KI) (Cramér $\mathrm{V}=0.775)$ was obtained with the diagnosis of $\mathrm{KC}$.

Conclusion:

Pentacam is a valuable tool in the analysis of corneal indices for the diagnosis of KC, given its high level of correlation with clinical refractive variables. The selection of candidates for refractive surgery, even when there is no diagnosis of $\mathrm{KC}$, is strengthened with the analysis of the corneal indices. The indices with the most intense level of dependence with the diagnosis of $\mathrm{KC}$ are, in order, the following indices: $\mathrm{CKI}$, $\mathrm{KI}$, vertical asymmetry, minimum radius, and variation of the surface.
\end{abstract}

Keywords: Keratoconus, Indices, Pentacam, Keratometry, Cylinder, Pachymetry.

\begin{tabular}{|l|c|c|c|}
\hline Article History & Received: April 4, 2020 & Revised: May 26, 2020 & Accepted: June 5, 2020 \\
\hline
\end{tabular}

\section{INTRODUCTION}

Keratoconus (KC) is a corneal ectatic disorder that tends to be bilateral in most cases and is characterized by a progressive corneal thinning that results in corneal protrusion, irregular astigmatism, and visual impairment [1,2]. Since the end of the last century, technological developments in this field have

* Address correspondence to this author at the University of Cuenca. Exilaser Ophthalmological Center, Cuenca, Ecuador; E-mail: drerojasalvarez@gmail.com enhanced the emergence of technologies that allow for an earlier and more effective $\mathrm{KC}$ diagnosis, thus decreasing long term complications associated with this disease.

Corneal topographic analysis has certainly been the most significant technological development. Corneal topography is a non-invasive imaging technique capable of representing the curvature, shape, and characteristics of a corneal surface effectively. 
Several commercial instruments that can be used to measure corneal thickness and curvatures are available, which vary according to the type of technology implemented. One of them is Pentacam, which is a system based on the Scheimpflug principle, with a great depth of focus that can be used to take pictures of a flat object that is not parallel to the image plane. It uses a rotating Scheimpflug camera and a monochromatic slit light source in combination with a static camera to obtain multiple images from specific angles through the optical axis [3].

Given the evident utility of corneal topographers, topographic indices have been developed, which are quantitative parameters that allow for the evaluation of the optical quality and corneal regularity in a more global way. Furthermore, they are algorithms that are included in most topographers, thus allowing for early diagnosis or an approach to the subclinical or clinical presence of corneal ectasia [4 - 6].

Corneal indices are numerical representations that simplify the interpretation of topographic results and the evolutionary study of corneal changes before and after surgery, thus acting as reference value controls [7 - 9]. They allow for a quantitative analysis of topographic information, and they are designed to simplify the distinction between normal corneas and pathological corneas even in subclinical states. They also include a combination of tomographic, topometric, and pachymetric parameters [6 - 9].

As corneal refractive surgery evolves, professional expectations are higher and continuous improvements on presurgical evaluation and interpretation, as well as detection strategies and data analysis strategies in order to avoid the inappropriate inclusion or exclusion of candidates, are required. Early and accurate $\mathrm{KC}$ detection using indices has been widely discussed, and the sensitivities and specificities of several parameters have been compared. In addition, new algorithms and combined indices have been introduced for achieving earlier and more accurate KC detection [10 - 12].

The purpose of this study is to describe the level of correlation between clinical refractive variables and corneal indices, demonstrate the usefulness of studying corneal indices for $\mathrm{KC}$ diagnosis and identify the corneal indices that have the most influence on $\mathrm{KC}$ diagnosis.

\section{MATERIALS AND METHODS}

A descriptive, retrospective, and cross-sectional study was carried out on 69 patients (138 eyes) who had refractive disorders and were possible candidates for corneal refractive surgery at Centro Oftalmológico Exiláser, Cuenca, Ecuador, from March to August 2019.

\subsection{Selection Criteria}

\section{Inclusion Criteria:}

-Patients with refractive disorders (myopia, astigmatism, hyperopia) who requested refractive surgery

\section{Exclusion Criteria:}

-Patients who had undergone one or more prior corneal refractive surgeries

\section{-Pregnant patients}

-Patients who had undergone corneal transplant surgery

-Patients who had used contact lenses over the last 3 months

Subjective and objective ophthalmologic examinations as well as corneal topographies (Pentacam) were performed on all study patients. According to the clinical and topographic characteristics observed, patients were diagnosed with KC. For $\mathrm{KC}$ diagnosis, the presence of topographic/tomographic criteria of the disease determined with Pentacam (Belin-Ambrosio Enhanced Ectasia Display) was considered, as well as the presence of clinical alterations observed in the physical examination, such as irregularities in the corneal reflex, Munson's sign, and Rizzuti's sign, and the presence of Fleischer's ring and Vogt's striae. Not all diagnosed cases had clinical characteristics in slit lamp; however, the diagnosis was made by topography, visual acuity and refraction. All cases with $\mathrm{KC}$ were bilateral. As a result, the sample was divided into two groups:

$$
\begin{aligned}
& \text { N1 }=\text { 92: Patients with KC } \\
& \text { N2 = 46: Patients without KC }
\end{aligned}
$$

\subsection{Study Variables}

Refractive cylinder: the refractive cylinder value expressed in the patient's subjective refraction (with a negative sign in the study), supported by autorefractometer and schiascopy, expressed in diopters.

Central pachymetry: measurement of the central corneal thickness expressed in micrometers. It is selected via Pentacam.

Central keratometry: the average of the corneal potency value observed in the 2, 3 and 4-mm diameter rings. It is expressed in diopters and selected via Pentacam.

Asphericity coefficient Q-value: it describes the changes in corneal curvature from the central to the peripheral areas. Value selected via Pentacam.

\subsection{Corneal Indices}

Surface Variation Index (SVI): shows the deviation of the individual corneal radius regarding the mean value. It can be normal (<37), abnormal (37-41), or pathological ( $\geq 41)$.

Vertical Asymmetry Index (VAI): shows the degree of symmetry between the corneal radius and the horizontal meridian. It can be normal $(<0.28)$, abnormal $(0.28-0.32)$, or pathological $(\geq 0.32)$.

Keratoconus Index (KI): it is defined as the relationship between the mean values of the curvature radius in the upper and lower corneal segments. It can be normal $(<1.07)$ or pathological $(\geq 1.07)$.

Central Keratoconus Index (CKI): it is the relationship between the mean values of the curvature radius in a peripheral Placido ring divided by a central ring. It can be normal $(<1.03)$ or pathological $(\geq 1.03)$.

Index of Height Asymmetry (IHA): shows the degree of 
symmetry between height data and the horizontal meridian. It can be normal $(<19)$, abnormal (19-21), or pathological $(\geq 21)$.

Index of Height Decentration (IHD): estimated using a Fourier analysis of height data and shows the degree of decentration in the vertical plane, which is calculated on a 3.0$\mathrm{mm}$ radius ring. It can be normal $(<0.014)$, abnormal (0.014-0.016), or pathological $(\geq 0.016)$.

Minimum Radius (minR): shows the lowest curvature radius in all the analyzed area. It is high in KC. It can be normal $(\leq 6.71)$ or pathological $(>6.71)$.

Methods for Data Collection, Statistical Analysis, and Ethical Aspects

Data were obtained from the clinical records and Pentacam Scheimpflug tomography (Allegro Oculyzer II, WaveLight $\mathrm{GmbH}$, Erlangen, Germany) results of each patient. Information was processed using SPSS 9.0 for Windows (SPSS, Inc.; Chicago, USA) package program. Pearson's correlation coefficient was obtained between the variables of interest and each studied corneal index, and a correlation matrix was determined. The mean value of each corneal index was obtained for both study groups, and a comparison of these mean values was made for each index using a T-test for the comparison of two independent population means. After this, the variances observed in both groups were compared (Levene's test) in order to determine their homoscedasticity and heteroscedasticity.
Subsequently, a categorical analysis of the different indicators was carried out. In order to do this, a category was assigned to each case (normal, suspicious, or pathological, according to the Pentacam values obtained for each index) and contingency tables were built for assessing the correlation between these categorical variables and KC. A multiple correspondence analysis of the categorical classification variables used for the different indicators was performed. For each case, a Fisher's exact test was applied for determining whether it was dependent or independent; if it was dependent (which was the case for all the tests performed), the direction of such dependence was assessed by an analysis of the corrected standardized residuals. Cramér's V coefficient was estimated to analyze the level of dependence.

\section{RESULTS}

As can be observed in Table 1, a direct statistically significant correlation was obtained between the refractive cylinder values and the corneal indices. That is to say that the higher a cylinder value is, the higher the corneal index is, this correlation being greater with the SVI.

As can be observed in Table $\mathbf{2}$, an inverse statistically significant correlation was obtained between the central pachymetry results and the corneal indices, this correlation being greater with the KI and the CKI. The lower a central pachymetry value is, the higher the KI and CKI values obtained.

Table 1. Correlation between refractive cylinder values and corneal indices.

\begin{tabular}{|c|c|c|}
\hline Index & Pearson & p \\
\hline SVI & $0.680^{* *}$ & 000 \\
\hline VAI & $0.481^{* *}$ & 0.000 \\
\hline KI & $0.456^{* *}$ & 0.000 \\
\hline CKI & $0.509^{* *}$ & 0.000 \\
\hline IHA & $0.425^{* *}$ & 0.000 \\
\hline IHD & $0.500^{* *}$ & 0.000 \\
\hline minR & $0.476^{* *}$ & 0.000 \\
\hline
\end{tabular}

**. Correlation is significant at the 0.01 level (bilateral).

Abbreviations: SVI (Surface variation index), VAI (Vertical asymmetry index), KI (Keratoconus index), CKI (Central keratoconus index), IHA (Index of height asymmetry), IHD (Index of height decentration), $\min R$ (Minimum radius).

Table 2. Correlation between central pachymetry results and corneal indices.

\begin{tabular}{|c|c|c|}
\hline Index & Pearson & P \\
\hline SVI & $-0.527^{* *}$ & 0.000 \\
\hline VAI & $-0.528^{* *}$ & 0.000 \\
\hline KI & $-0.645^{* *}$ & 0.000 \\
\hline CKI & $-0.758^{* *}$ & 0.000 \\
\hline IHA & $-0.359^{* *}$ & 0.000 \\
\hline IHD & $-0.578^{* *}$ & 0.000 \\
\hline minR & $-0.423^{* *}$ & 0.000 \\
\hline
\end{tabular}

**. Correlation is significant at the 0.01 level (bilateral).

Abbreviations: SVI (Surface variation index), VAI (Vertical asymmetry index), KI (Keratoconus index), CKI (Central keratoconus index), IHA (Index of height asymmetry), IHD (Index of height decentration), minR (Minimum radius). 
As can be observed in Table $\mathbf{3}$, a direct statistically significant correlation was obtained between the central keratometry value (central $\mathrm{K}$ ) and the corneal indices, this correlation being greater with the KI and the CKI. The higher a central keratometry value is, the higher the $\mathrm{KI}$ and CKI values obtained.

Regarding the asphericity coefficient (Q-value), as shown in Table 4, the correlation coefficients obtained show a weak inverse relationship between the asphericity coefficient and the corneal indices.

Table 5 shows the mean value for each corneal index in both study groups. When comparing these values, statistically significant differences were obtained between patients with $\mathrm{KC}$ and those without $\mathrm{KC}$.

Table 6 shows the level of dependence of corneal indices with $\mathrm{KC}$ presence. Indices with the highest level of dependency are: CKI, KI, VAI, minR, and SVI.

Table 3. Correlation between central keratometry and corneal indices.

\begin{tabular}{|c|l|c|}
\hline Index & Pearson & p \\
\hline SVI & $0.567^{* *}$ & 0.000 \\
\hline VAI & $0.481^{* *}$ & 0.000 \\
\hline KI & $0.668^{* *}$ & 0.000 \\
\hline CKI & $0.778^{* *}$ & 0.000 \\
\hline IHA & $0.286^{* *}$ & 0.000 \\
\hline IHD & $0.599^{* *}$ & 0.000 \\
\hline minR & $0.447^{* *}$ & 0.000 \\
\hline
\end{tabular}

**. Correlation is significant at the 0.01 level (bilateral).

Abbreviations: SVI (Surface variation index), VAI (Vertical asymmetry index), KI (Keratoconus index), CKI (Central keratoconus index), IHA (Index of height asymmetry), IHD (Index of height decentration), minR (Minimum radius).

Table 4. Correlation between asphericity coefficient $Q$-values and corneal indices.

\begin{tabular}{|c|c|c|}
\hline Index & Pearson & p \\
\hline SVI & $-0.356^{* *}$ & 0.000 \\
\hline VAI & $-0.169^{*}$ & 0.047 \\
\hline KI & $-0.229^{* *}$ & 0.007 \\
\hline CKI & $-0.371^{* *}$ & 0.000 \\
\hline IHA & -0.140 & 0.102 \\
\hline IHD & $-0.218^{*}$ & 0.010 \\
\hline minR & -0.176 & 0.012 \\
\hline
\end{tabular}

** Correlation is significant at the 0.01 level (bilateral).

* Correlation is significant at the 0.05 level (bilateral).

Abbreviations: SVI (Surface variation index), VAI (Vertical asymmetry index), KI (Keratoconus index), CKI (Central keratoconus index), IHA (Index of height asymmetry), IHD (Index of height decentration), minR (Minimum radius).

Table 5. Comparison between mean index values obtained for both groups.

\begin{tabular}{|c|c|c|c|c|}
\hline - & Keratoconus & $\mathbf{N}$ & Mean & $\mathbf{p}$ \\
\hline \multirow{2}{*}{ SVI } & No & 92 & $29.1522 \pm 1.18821$ & \multirow[t]{2}{*}{$<0.0001$} \\
\hline & Yes & 46 & $74.2959 \pm 5.36396$ & \\
\hline \multirow{2}{*}{ VAI } & No & 92 & $0.1635 \pm .01327$ & \multirow[t]{2}{*}{$<0.0001$} \\
\hline & Yes & 46 & $0.6511 \pm .05918$ & \\
\hline \multirow{2}{*}{ KI } & No & 92 & $1.0249 \pm .00295$ & \multirow[t]{2}{*}{$<0.0001$} \\
\hline & Yes & 46 & $1.1948 \pm .02021$ & \\
\hline \multirow{2}{*}{ CKI } & No & 92 & $1.0097 \pm .00108$ & \multirow[t]{2}{*}{$<0.0001$} \\
\hline & Yes & 46 & $1.0674 \pm .00710$ & \\
\hline \multirow{2}{*}{$\min R$} & No & 92 & $7.3890 \pm .02948$ & \multirow[t]{2}{*}{$<0.0001$} \\
\hline & Yes & 46 & $6.3359 \pm .24087$ & \\
\hline \multirow{2}{*}{ IHA } & No & 92 & $6.654 \pm .7573$ & \multirow[t]{2}{*}{$<0.0001$} \\
\hline & Yes & 46 & $25.763 \pm 3.7786$ & \\
\hline
\end{tabular}

Abbreviations: SVI (Surface variation index), VAI (Vertical asymmetry index), KI (Keratoconus index), CKI (Central keratoconus index), IHA (Index of height asymmetry), IHD (Index of height decentration), $\operatorname{minR}$ (Minimum radius). 
Table 6. Dependence level of corneal indices with KC diagnosis.

\begin{tabular}{|c|c|}
\hline Indicator & Cramér's V \\
\hline Q & 0.409 \\
\hline SVI & 0.682 \\
\hline VAI & 0.755 \\
\hline KI & 0.775 \\
\hline CKI & 0.785 \\
\hline minR & 0.754 \\
\hline IHA & 0.556 \\
\hline
\end{tabular}

Abbreviations: Q (corneal asphericity coefficient), SVI (Surface variation index), VAI (Vertical asymmetry index), KI (Keratoconus index), CKI (Central keratoconus index), IHA (Index of height asymmetry), IHD (Index of height decentration), minR (Minimum radius).

Table 7. Summary of the multiple correspondence analysis model.

\begin{tabular}{|c|c|c|c|c|}
\hline \multicolumn{5}{|c|}{ Summary of the model } \\
\hline \multirow[t]{2}{*}{ Dimension } & \multirow[t]{2}{*}{ Cronbach's alpha } & \multicolumn{3}{|c|}{ Variance explained } \\
\hline & & Total (Autovalues) & Inertia & $\%$ of variance \\
\hline 1 & 0.937 & 5.565 & 0.696 & 69.559 \\
\hline 2 & 0.144 & 1.145 & 0.143 & 14.309 \\
\hline Total & - & 6.709 & 0.839 & - \\
\hline Mean & $0.802^{\mathrm{a}}$ & 3.355 & 0.419 & 41.934 \\
\hline
\end{tabular}

a. Average Cronbach's alpha is based on average autovalues.

Table 8. Multiple correspondence analysis model.

\begin{tabular}{|c|c|c|c|}
\hline \multicolumn{4}{|c|}{ Discrimination measures } \\
\hline \multirow[t]{2}{*}{-} & \multicolumn{2}{|c|}{ Dimension } & \multirow[t]{2}{*}{ Mean } \\
\hline & 1 & 2 & \\
\hline CKI1 & 0.757 & 0.005 & 0.381 \\
\hline Q1 & 0.314 & 0.039 & 0.177 \\
\hline SVI1 & 0.711 & 0.440 & 0.575 \\
\hline AVI1 & 0.815 & 0.118 & 0.467 \\
\hline KI1 & 0.782 & 0.000 & 0.391 \\
\hline CKI1 & 0.863 & 0.002 & 0.432 \\
\hline $\min R 1$ & 0.843 & 0.001 & 0.422 \\
\hline IHA1 & 0.480 & 0.539 & 0.509 \\
\hline Total active & 5.565 & 1.145 & 3.355 \\
\hline$\%$ of variance & 69.559 & 14.309 & 41.934 \\
\hline
\end{tabular}

Abbreviations: Q (corneal asphericity coefficient), SVI (Surface variation index), VAI (Vertical asymmetry index), KI (Keratoconus index), CKI (Central keratoconus index), IHA (Index of height asymmetry), IHD (Index of height decentration), minR (Minimum radius).

A multiple correspondence analysis was performed on the categorical variables used to classify the different indicators. It can be observed that both dimensions together account for $83.9 \%$ of the total variability, Dimension 1 being the most significant as it accounts for $69.6 \%$ of the total variability (Tables 7 and $\mathbf{8}$ ).

Dimension 1 includes most of the evaluated indicators (KC, Q, SVI, VAI, KL, CKL, and minR); although IHA is significantly represented in Dimension 1 , it is also significantly represented in Dimension 2, as can be observed in Table 7.

The presence of KC (yes) is highly correlated with the pathological cases observed in the different indicators, with small distances between them, whereas the absence of $\mathrm{KC}$ (no) is highly correlated with the normal cases observed in the different indicators as well as in the suspicious indicators of SVI and, at a lower level (higher distance) with the altered cases of the same indicator. $\mathrm{KC}$ values (yes or no) should not be correlated with altered IHA values.

\section{DISCUSSION}

All the corneal indices studied showed a direct association with the refractive cylinder value. Patients with high cylinder values have a greater alteration of the corneal indices toward 
figures that are considered pathological. The fact that a patient has a high cylinder value in his or her refraction formula is highly important in the examination for a possible ectasia; however, refractive cylinder results with more than 4 diopters may exist, with alterations in the corneal indices yielded by Pentacam, and without corneal ectasia. Therefore, it is important to consider the remaining clinical variables of each patient as well as the pachymetry results. One of the indices with the highest correlation with the refractive cylinder value was the SVI, which shows the deviation of the individual corneal radius regarding the mean value.

Regarding their association with pachymetry results, all the corneal indices increase up to figures that are considered to be pathological as the patient's central pachymetry value decreases. This correlation was greater with KI and CKI, which include the patient's pachymetry value in their analysis, thus turning into more comprehensive and specific indices for corneal ectasia diagnosis. Nevertheless, it is necessary to highlight that, although the remaining indices do not include corneal pachymetry results within their analysis, the changes observed toward pathological figures are particularly sensitive in patients with decreased pachymetry results.

Similar results were obtained with central keratometry, which directly correlated with several indices, particularly with $\mathrm{KI}$ and CKI, evidencing once more the influence of a high corneal curvature in the diagnosis of corneal ectasia. The lowest correlation was observed with the IHA.

Corneal asphericity coefficient Q-values did not show a correlation with the corneal index values obtained. The Qvalue describes the changes in the corneal curvature from the central to the peripheral area.

The significant differences obtained between the mean index values estimated for both study groups suggest their usefulness in the diagnosis of corneal ectasia, which has been widely demonstrated in different studies [13 - 15]. However, further research into some elements that specify the variations observed in these values and their relationship with $\mathrm{KC}$ diagnosis is necessary. According to the results obtained, there are indices with a greater dependency level regarding $\mathrm{KC}$ diagnosis, such as CKI, KI, VAI, and SVI.

In this sense, we agree with prior researchers who showed CKI as a parameter for refractive detection which is highly capable of discriminating clinical $\mathrm{KC}$ from normal eyes [16 19]. Besides, research studying CKI increase and its relationship with early $\mathrm{KC}$ has been conducted. Bae reports an increase of CKI in the healthy eye of patients with unilateral $\mathrm{KC}$; however, Huseynli reported that $\mathrm{CKI}$ is a poor parameter for preKC distinction $[18,20]$. CKI is a valuable index capable of providing a quick reference in the identification of frank $\mathrm{KC}$, and it is also highly useful to confirm clinical suspicions when used as a cross-reference parameter in relation to other indices.

According to the results obtained in this research, $\mathrm{KI}$ is one of the indices with the highest levels of dependence on $\mathrm{KC}$, and it certainly represents an efficient diagnostic test used to discriminate between normal eyes and $\mathrm{KC}$ eyes. In this sense, we did not obtain results that were similar to the ones reported by Chan, who showed a KI diagnostic accuracy lower than other Pentacam indices obtained for KC diagnosis [16]. In contrast, the results obtained are consistent with those reported by Orucoglu, who states that $\mathrm{KI}$ is an excellent indicator of $\mathrm{KC}$ diagnosis, with sensitivity and specificity levels higher than $90 \%$, which are even higher than the ones obtained for CKI $[21,22]$. Huseynli and Bae suggest that KI application should be limited to preKC patients $[18,20]$.

VAI is another parameter in which we obtained a high dependency level to the presence of corneal ectasia. Shetty obtained a high level of sensitivity in this index as a parameter for $\mathrm{KC}$ diagnosis [23]. Hashemi found that VAI was useful in preKC cases [17]. Arbelaez carried out a study with an index that was similar to the VAI, which showed a high predictive ability for preKC [24]. The importance of this index for diagnosing $\mathrm{KC}$ and determining the predictability of the disease is very clear; however, as it also happens with the previously analyzed indices, its full validity in preKC cases has not been shown.

SVI is also a highly sensitive parameter for KC diagnosis as it reflects the presence of irregular astigmatism. These results are consistent with those reported by different authors: a pathological SVI shows alterations of the corneal curvature $[11,17,23]$. Conversely, results that confirm its utility in preKC cases have also been obtained $[22,25]$. An aspect that highlights the usefulness of this index demonstrated its importance in the postoperative follow-up of patients, as well as in $\mathrm{KC}$ progression in longitudinal analysis. In this sense, Kanellopoulos reports a high SVI sensitivity [26].

According to the results obtained, IHA, as opposed to the previously analyzed indices, did not have a high level of dependence on corneal ectasia. Different authors show a high sensitivity of IHA in $\mathrm{KC}$ detection and low sensitivity in preKC detection; for this reason, it is not very useful for the detection of the earliest corneal changes occurring toward ectasia $[18,20,23]$.

The results obtained for IHD were similar to those obtained for IHA. Bae states its usefulness in unilateral KC cases; besides, IHD has proven to be highly useful in preKC cases with high diagnostic accuracy [20]. However, Shetty states that this parameter lacks clinical accuracy in this sense [23]. Studies carried out in order to assess the usefulness of an index in preKC cases are always conditioned by selection bias in one way or another because the selection criteria for preKC cases as well as their definition may be controversial and may vary among several authors (subclinical, suspicious, and frustrated).

It is important to highlight that, regardless of the considerable usefulness of corneal indices in $\mathrm{KC}$ diagnosis, ophthalmologists should act based on the clinical criteria established for the disease, such as visual acuteness assessment, corneal aberration examination, family KC history, presence of an ocular allergy, and/or chronic eye-rubbing patients. They should not analyze corneal indices as isolated rigid variables as they are not capable of diagnosing corneal ectasia. The validity of the clinical method does not decrease with the analysis of these indices; on the contrary, it becomes stronger.

Ophthalmologists should not omit the area where their patients are examined; studies that identify regional differences in $\mathrm{KC}$ regarding its morphology and areas of higher prevalence are increasingly frequent [27-29]. This research was carried out in a city where a higher $\mathrm{KC}$ prevalence was reported in 
comparison with the rest of the country; for this reason, if the examination takes place in areas with these characteristics, the index analysis should be deeper and be further selective when choosing candidates for corneal refractive procedures [30].

In contrast, the development of Pentacam as a diagnostic method has been optimized with new applications that go beyond the analysis of corneal indices. The Belin-Ambrosio analysis allows for a more comprehensive assessment of patients because of its multivariate potential, which has a greater contribution in patients with preKC as opposed to the study of corneal indices [31 - 34].

Current limitations of corneal indices include the fact that they have not been cross-validated for several reference surfaces. The Best-Fit Sphere (BFS) is the most common reference method; however, it may not be possible to apply it in patients with irregular astigmatism or severe astigmatism. For this reason, it is necessary to carry out index analysis with an improved BFS (better than the conventional BFS) and the best-fit toric ellipsoid (which is a better reference, used to identify cone height) $[35,36]$.

The study of corneal indices in specific populations with different age groups is another necessary aspect; most of the Pentacam normative database was obtained from refractive surgery candidates aged between 21 and 40 years old; moreover, for studying regional variabilities that may exist regarding emmetropic patients, patients with refractive defects and patients with corneal ectasia should be studied [18, 37 42]. It is also important to perform multicentric research on corneal indices of patients with preKC and to agree upon patient selection criteria. Another aspect to be considered is the determination of a corneal index capable of characterizing the predictability and the evolution of this disease.

\section{CONCLUSION}

Pentacam is a valuable tool in the analysis of corneal indices for $\mathrm{KC}$ diagnosis because of its high level of correlation with clinical refractive variables. The index values increase up to figures considered to be pathological in patients with high refractive cylinders, elevated keratometry results, and low pachymetry results.

The selection of candidates for refractive surgery, even when there is no $\mathrm{KC}$ diagnosis, is supported by the analysis of corneal indices because of the remarkable differences in the index values observed in patients without and with $\mathrm{KC}$.

Indices with the highest dependency level toward $\mathrm{KC}$ diagnosis include, from the highest to the lowest level: CKI, KI, VAI, minR, and SVI.

The validity of the clinical methods does not decrease with the analysis of these indices.

\section{LIST OF ABBREVIATIONS}

$\begin{array}{lll}\text { Q } & = & \text { Corneal Asphericity Coefficient } \\ \text { SVI } & = & \text { Surface Variation Index. } \\ \text { VAI } & = & \text { Vertical Asymmetry Index. } \\ \text { KI } & = & \text { Keratoconus Index. } \\ \text { CKI } & = & \text { Central Keratoconus Index. }\end{array}$

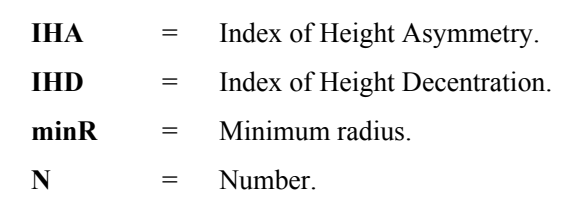

ETHICS APPROVAL AND CONSENT TO

\section{PARTICIPATE}

This study was approved by the Bioethics Committee of the Exilaser Ophthalmological Center, Cuenca, Ecuador (under approval number 9).

\section{HUMAN AND ANIMAL RIGHTS}

No animals were used in this research. All human research procedures followed were in accordance with the ethical standards of the committee responsible for human experimentation (institutional and national), and with the Helsinki Declaration of 1975, as revised in 2013.

\section{CONSENT FOR PUBLICATION}

Informed written consent was obtained from all the patients when they were enrolled.

\section{AVAILABILITY OF DATA AND MATERIALS}

The databases of the current research are the property of the authors and are part of the statistical information of the Exilaser Ophthalmological Center, for which reason it is not possible to share it. Furthermore, these data will form part of future research by the institution.

\section{FUNDING}

None.

\section{CONFLICT OF INTEREST}

The authors declare no conflict of interest, financial or otherwise.

\section{ACKNOWLEDGEMENTS}

Declared none.

\section{REFERENCES}

[1] Rabinowitz YS. Keratoconus. Surv Ophthalmol 1998; 42(4): 297-319. [http://dx.doi.org/10.1016/S0039-6257(97)00119-7] [PMID: 9493273]

[2] Krachmer JH, Feder RS, Belin MW. Keratoconus and related noninflammatory corneal thinning disorders. Surv Ophthalmol 1984; 28(4): 293-322.

[http://dx.doi.org/10.1016/0039-6257(84)90094-8] [PMID: 6230745]

[3] Meyer JJ, Gokul A, Vellara HR, Prime Z, McGhee CN. Vellara HR, Prime Z, McGhee CN.. Repeatability and agreement of Orbscan II, Pentacam HR, and Galilei tomography systems in corneas with keratoconus. Am J Ophthalmol 2017; 175: 122-8. [http://dx.doi.org/10.1016/j.ajo.2016.12.003] [PMID: 27993593]

[4] Salomão M, Hoffling-Lima A, Lopes B, et al. Recent developments in keratoconus diagnosis. Expert Rev Ophthalmol 2018; 13: 329-41. [http://dx.doi.org/10.1080/17469899.2018.1555036] 
[5] Ambrósio R Jr, Valbon BF, Faria-Correia F, Ramos I, Luz A. Scheimpflug imaging for laser refractive surgery. Curr Opin Ophthalmol 2013; 24(4): 310-20

[http://dx.doi.org/10.1097/ICU.0b013e3283622a94] [PMID: 23680761]

[6] Martin R, Jonuscheit S, Rio-Cristobal A, Doughty MJ. Repeatability of Pentacam peripheral corneal thickness measurements. Cont Lens Anterior Eye 2015; 38(6): 424-9.

[http://dx.doi.org/10.1016/j.clae.2015.05.001] [PMID: 26072988]

[7] Guber I, McAlinden C, Majo F, Bergin C. Identifying more reliable parameters for the detection of change during the follow-up of mild to moderate keratoconus patients. Eye Vis (Lond) 2017; 4: 24. [http://dx.doi.org/10.1186/s40662-017-0089-3] [PMID: 29124079]

[8] Gomes JA, Tan D, Rapuano CJ, et al. Group of Panelists for the Global Delphi Panel of Keratoconus and Ectatic Diseases. Global consensus on keratoconus and ectatic diseases. Cornea 2015; 34(4): 359-69.

[http://dx.doi.org/10.1097/ICO.0000000000000408]

[PMID: 25738235]

[9] Wahba SS, Roshdy MM, Elkitkat RS, Naguib KM. Rotating Scheimpflug imaging indices in different grades of keratoconus. J Ophthalmol 2016; 20166392472

[http://dx.doi.org/10.1155/2016/6392472] [PMID: 27579178]

[10] Febbraro J-L, Khan H, Koch D. Surgical correction of astigmatism. Cham: Springer International Publishing 2018.

[http://dx.doi.org/10.1007/978-3-319-56565-1]

[11] Piñero DP, Nieto JC, Lopez-Miguel A. Characterization of corneal structure in keratoconus. J Cataract Refract Surg 2012; 38(12): 2167-83.

[http://dx.doi.org/10.1016/j.jcrs.2012.10.022] [PMID: 23195256]

[12] Ambrósio R Jr, Randleman JB. Screening for ectasia risk: what are we screening for and how should we screen for it? J Refract Surg 2013; 29(4): 230-2.

[http://dx.doi.org/10.3928/1081597X-20130318-01] [PMID: 23557219]

[13] Crawford AZ, Patel DV, McGhee CN. Comparison and repeatability of keratometric and corneal power measurements obtained by Orbscan II, Pentacam, and Galilei corneal tomography systems. Am J Ophthalmol 2013; 156(1): 53-60.

[http://dx.doi.org/10.1016/j.ajo.2013.01.029] [PMID: 23540708]

[14] Montalbán R, Piñero DP, Javaloy J, Alió JL. Intrasubject repeatability of corneal morphology measurements obtained with a new Scheimpflug photography-based system. J Cataract Refract Surg 2012; 38(6): 971-7.

[http://dx.doi.org/10.1016/j.jcrs.2011.12.029] [PMID: 22541828]

[15] McAlinden C, Khadka J, Pesudovs K. A comprehensive evaluation of the precision (repeatability and reproducibility) of the Oculus Pentacam HR. Invest Ophthalmol Vis Sci 2011; 52(10): 7731-7. [http://dx.doi.org/10.1167/iovs.10-7093] [PMID: 21810981]

[16] Chan TC, Wang YM, Yu M, Jhanji V. Comparison of corneal dynamic parameters and tomographic measurements using Scheimpflug imaging in keratoconus. Br J Ophthalmol 2018; 102(1): $42-7$. [http://dx.doi.org/10.1136/bjophthalmol-2017-310355] [PMID: 28559422]

[17] Hashemi H, Khabazkhoob M, Pakzad R, et al. Pentacam accuracy in discriminating keratoconus from normal corneas: A diagnostic evaluation study. Eye Contact Lens 2019; 45(1): 46-50.

[http://dx.doi.org/10.1097/ICL.0000000000000531] [PMID: 30005053]

[18] Huseynli S, Abdulaliyeva F. Evaluation of Scheimpflug tomography parameters in subclinical keratoconus, clinical keratoconus and normal Caucasian eyes. Turk J Ophthalmol 2018; 48(3): 99-108. [http://dx.doi.org/10.4274/tjo.89587] [PMID: 29988819]

[19] Kovács I, Miháltz K, Kránitz K, et al. Accuracy of machine learning classifiers using bilateral data from a Scheimpflug camera for identifying eyes with preclinical signs of keratoconus. J Cataract Refract Surg 2016; 42(2): 275-83.

[http://dx.doi.org/10.1016/j.jcrs.2015.09.020] [PMID: 27026453]

[20] Bae GH, Kim JR, Kim CH, Lim DH, Chung ES, Chung TY. Corneal topographic and tomographic analysis of fellow eyes in unilateral keratoconus patients using Pentacam Am J Ophthalmol 2014; 157 : 103-9.

[21] Orucoglu F, Toker E. Comparative analysis of anterior segment parameters in normal and keratoconus eyes generated by scheimpflug tomography. J Ophthalmol 2015; 2015925414

[http://dx.doi.org/10.1155/2015/925414] [PMID: 25878897]

[22] Oruçoğlu F, Toker E. A Novel scoring system for distinguishing keratoconus from normal eyes. Cont Lens Anterior Eye 2016; 39(5): 369-74.

[http://dx.doi.org/10.1016/j.clae.2016.07.002] [PMID: 27478053]

[23] Shetty R, Rao H, Khamar P, et al. Keratoconus screening indices and their diagnostic ability to distinguish normal from ectatic corneas. Am J Ophthalmol 2017; 181: 140-8

[http://dx.doi.org/10.1016/j.ajo.2017.06.031] [PMID: 28687218]

[24] Arbelaez MC, Versaci F, Vestri G, Barboni P, Savini G. Use of a support vector machine for keratoconus and subclinical keratoconus detection by topographic and tomographic data. Ophthalmology 2012; 119(11): 2231-8.

[http://dx.doi.org/10.1016/j.ophtha.2012.06.005] [PMID: 22892148]

[25] Luz A, Ramos I, Correia FF, Lopes B, Salomão MQ, Correa RO. Topometric and tomographic indices for the diagnosis of keratoconus. IJKECD 1: 92

[26] Kanellopoulos AJ, Asimellis G. Revisiting keratoconus diagnosis and progression classification based on evaluation of corneal asymmetry indices, derived from Scheimpflug imaging in keratoconic and suspect cases. Clin Ophthalmol 2013; 7: 1539-48

[http://dx.doi.org/10.2147/OPTH.S44741] [PMID: 23935360]

[27] Gordon-Shaag A, Millodot M, Shneor E, Liu Y. The genetic and environmental factors for keratoconus. BioMed Res Int 2015; 2015795738

[http://dx.doi.org/10.1155/2015/795738] [PMID: 26075261]

[28] Gokhale NS. Epidemiology of keratoconus. Indian J Ophthalmol 2013; 61(8): 382-3.

[http://dx.doi.org/10.4103/0301-4738.116054] [PMID: 23925318]

[29] Kok YO, Tan GF, Loon SC. Review: Keratoconus in Asia. Cornea 2012; 31(5): 581-93

[http://dx.doi.org/10.1097/ICO.0b013e31820cd61d]

[PMID: 22314815]

[30] Rojas-Alvarez E. Queratocono en edad pediátrica. Características clínico refractivas y evolución. Centro de especialidades médicas Fundación Donum, Cuenca, Ecuador, 2015-2018. Rev Mex Oftalmol 2019; 93: 221-32.

[http://dx.doi.org/10.24875/RMO.M19000082]

[31] Ferreira-Mendes J, Lopes BT, Faria-Correia F, Salomão MQ, Rodrigues-Barros S, Ambrósio R Jr. Enhanced ectasia detection using corneal tomography and biomechanics. Am J Ophthalmol 2019; 197 : 7-16.

[http://dx.doi.org/10.1016/j.ajo.2018.08.054] [PMID: 30201341]

[32] Lopes BT, Ramos IC, Dawson DG, Belin MW, Ambrósio R Jr. Detection of ectatic corneal diseases based on pentacam. Z Med Phys 2016; 26(2): 136-42.

[http://dx.doi.org/10.1016/j.zemedi.2015.11.001] [PMID: 26777318]

[33] Villavicencio OF, Gilani F, Henriquez MA, Izquierdo L, Ambrósio RR. Independent population validation of the Belin/Ambrósio enhanced ectasia display: Implications for keratoconus studies and screening. Int J Keratoconus Ectatic Corneal Diseases 2014; 3: 1-8. [http://dx.doi.org/10.5005/jp-journals-10025-1069]

[34] Ambrósio R Jr, Ramos I, Lopes B, et al. Assessing ectasia susceptibility prior to LASIK: the role of age and residual stromal bed (RSB) in conjunction to Belin-Ambrósio deviation index (BAD-D). Rev Bras Oftalmol 2014; 73.

[http://dx.doi.org/10.5935/0034-7280.20140018]

[35] Belin MW, Ambrósio R. Scheimpflug imaging for keratoconus and ectatic disease. Indian J Ophthalmol 2013; 61(8): 401-6.

[http://dx.doi.org/10.4103/0301-4738.116059] [PMID: 23925323]

[36] Sinjab MM. Classifications and Patterns of Keratoconus and Keratectasia.Quick guide to the management of keratoconus, Springer Berlin Heidelberg, Berlin. Heidelberg 2012; pp. 13-58. [http://dx.doi.org/10.1007/978-3-642-21840-8_2]

[37] Roshdy MMS, Wahba SS, Elkitkat RS, Hakim AM, Fikry RR. Effect of age on Pentacam keratoconus indices. J Ophthalmol 2018; 20182016564

[http://dx.doi.org/10.1155/2018/2016564] [PMID: 29850200]

[38] Uçakhan ÖÖ, Cetinkor V, Özkan M, Kanpolat A. Evaluation of Scheimpflug imaging parameters in subclinical keratoconus, keratoconus, and normal eyes. J Cataract Refract Surg 2011; 37(6): 1116-24.

[http://dx.doi.org/10.1016/j.jcrs.2010.12.049] [PMID: 21596255]

[39] Feng MT, Belin MW, Ambrósio R Jr, et al. International values of corneal elevation in normal subjects by rotating Scheimpflug camera. $\mathrm{J}$ Cataract Refract Surg 2011; 37(10): 1817-21.

[http://dx.doi.org/10.1016/j.jcrs.2011.04.030] [PMID: 21840680]

[40] Feng MT, Belin MW, Ambrósio R Jr, et al. Anterior chamber depth in normal subjects by rotating scheimpflug imaging. Saudi J Ophthalmol 
2011; 25(3): 255-9.

[http://dx.doi.org/10.1016/j.sjopt.2011.04.005] [PMID: 23960933]

[41] Gilani F, Cortese M, Ambrósio RR Jr, et al. Comprehensive anterior segment normal values generated by rotating Scheimpflug tomography. J Cataract Refract Surg 2013; 39(11): 1707-12. [http://dx.doi.org/10.1016/j.jcrs.2013.05.042] [PMID: 24054966]

[42] Kim J, Cortese MW, Belin M, Ambrosio RS Jr, Khachikian S. Tomographic normal values for corneal elevation and pachymetry in a hyperopic population. J Clin Exp Ophthalmol 2011; 2: 1-4.

\section{2020 Alvarez et al.}

This is an open access article distributed under the terms of the Creative Commons Attribution 4.0 International Public License (CC-BY 4.0), a copy of which is available at: (https://creativecommons.org/licenses/by/4.0/legalcode). This license permits unrestricted use, distribution, and reproduction in any medium, provided the original author and source are credited. 